\title{
Social Media Usage of Small and Medium Sized Companies: Do they Get a Competitive Advantage?
}

\section{Gülçin İpek Emeksiz}

Anadolu University, Turkey

giemeksiz@anadolu.edu.tr

\begin{abstract}
Facebook is still the leading social networking site in the world that people primarily use to connect with their friends, share their thoughts and feelings, catch up with the news and trends in their surroundings and follow their favourite brands. Since Facebook is a cost-effective tool, many multinational large sized companies from a variety of sectors worldwide have opened brand fan pages on Facebook to reach their target audience conveniently. These large sized companies cooperating with social media agencies and implementing a corporate communication strategy on their Facebook brand fan pages gain many benefits from their Facebook usage. However, few research have examined so far how small and medium sized enterprises, whose budgets are limited comparative to large sized companies, can gain some benefits from their Facebook usage. This research aims to look at how small and medium sized enterprises use Facebook for business purposes and whether they may get a competitive advantage from their Facebook usage.
\end{abstract}

Keywords: Facebook, small and medium sized companies, communication, competitive advantage

\section{Introduction}

As social media usage has been widespread among individuals throughout the world, many large sized companies have kept up with this new trend and commenced to use social media tools in their corporate communication activities. As Facebook has 2.01 billion monthly active Facebook users globally (Zephoria Digital Marketing, 2017), this social media platform has given excitement to companies who are willing to open brand fan pages to reach their target audience.

Therefore, numerous large sized companies who want to influence their potential and prospective customers have seen platforms such as Facebook as a great opportunity to introduce their products and services. What is worth to underline that these companies generally work with social media representatives at digital agencies who create daily content for their products and services. It is, in fact, social media representatives who manage the conversations on their Facebook brand pages.

Since social media is based on two-way dialogue, companies can easily communicate with their customers on their Facebook brand fan pages. They can directly learn what their customers' needs and they can come up with practical suggestions. This way, they can improve their customer satisfaction significantly. Therefore, managing Facebook brand fan pages properly is an important task for companies since it has a direct effect on corporate reputation.

Large sized companies use many tactics to pull more customers to their Facebook pages. Organizing competitions and giving gifts are some of the common tactics that many of 
them prefer in the beginning. In fact, how companies communicate with their customers, the way they use the language and the corporate communication strategy they apply to their Facebook brand fan pageshave the most influence on their goal of pulling more customers.

Banyai (2016) mentions that Facebook usage brings many advantages to large size companies such as gaining customer insights and developing new products with their customers' suggestions. Large size companies also provide customer support after product purchase on Facebook. They improve their communication with their customers thanks to interactions and raise their sales as a result. (Banyai, 2016: 243).

Small and medium sized companies, which had realized the advantages of social media such as connecting with customers and making new business connections, started to create profiles on Facebook just as large size companies. However, according to Kasteler (2011) a major handicap of small and medium size companies compared with large size companiesresults from the fact that they lack a deep-rooted brandhistory and brand experience in the business market. (Kasteler, 2011). Therefore, people tend to gather in the Facebook brand communities of large size companies that they know well first. Because of that, small and medium size companies cannot reach millions of Facebook likes just as quickly as large size companies.

Moreover, adapting to the social media technology is challenging for small and medium sized enterprises because they commonly lack the technological infrastructure and they don't have an experienced social media team. They usually experience social media by trying and observing. In other words, for small and medium sized enterprises the biggest handicap is the lack of resources to use social media professionally.

The research of Roy, Maxwell and Carson on small and medium sized enterprises in Arkansas, U.S.A demonstrates that the usage of social media mainly depends on having a sufficient budget and accessibility of technical support for small and medium sized companies (Roy, Maxwell and Carson, 2014: 134). In addition, Karimi and Naghibi (2015) underlines that managing a social media profile page for a company takes a lot of time as it requires a social media team who will produce fresh content, answer the questions and take attention of the complaints of customers in time (Karimi and Naghibi, 2015: 91).

Carlota, Constantinides, and Maria-del-Carmen(2014) mention that a small company needs technical support instead of market experience in order to use social media efficiently and companies which use social media frequently has at least two IT experts within their bodies (Carlota, Constantinides, and Maria-del-Carmen,2014: 205). Thus, small companies need full time employees who will manage their social media accounts and who will create interaction with the customers by answering their requests, suggestions and complaints.

Nevertheless, small and medium sized enterprises don't usually have a social media team who has experience in shaping the dialogues with their customers. Also, Kasteler (2011) points out that when the person who is in charge of social media in small companies goes to a vacation for a week, then there is nobody left to take care of the Facebook account, which means the delay of responding to comments (Kasteler, 2011) Thus, many small and medium sized enterprises generally prefer one-way communication on social media which is directly from the company to the customers.

For instance, He, Wang and Zha (2014) examined the Facebook pages of 32 small pizzerias in U.S.A and found out that most of these pizzerias failed in giving a timely response to their customers and thus He, Wang and Zha suggested that these pizzerias 
should create a static website instead of taking place on Facebook brand fan pages (He, Wang and Zha, 2014: 243).

Furthermore, another disadvantage of small and medium sized enterprises compared to large size companies is that they usually lack a social media strategy. Roy and Dionne (2014) interviewed four small and medium sized enterprises in the tourism sector in Canada and the results revealed that these enterprises didn't have a social media strategy that they applied on social media; instead the content was created arbitrary by the person who was responsible from the social media platforms (Roy and Dionne, 2014: 454).

In other words, the biggest deficiency of small companies compared to large sized companies is that they lack a social media strategy on Facebook. Since small companies usually do not have an experienced technical staff who can plan and manage social media effectively, small companies have a major disadvantage.

Because of these various reasons, many small and medium sized enterprisesare hesitant about entering into the social media atmosphere in the beginning. The research of Beesly on small and medium sized enterprises apparently show that most of them create excuses about not finding enough time to make the site look nice-lookingor not having enough updates to attract new customers. (Beesly, 2013). Thus, some of the small and medium sized enterprises tend to give up from their social media usage early.

On the other hand, social media usage may bring a competitive advantage to small and medium sized enterprises because as Kadam and Ayarekar point out small and medium sized enterprisestry to survive in a competitive business environment (Kadam and Ayarekar, 2014: 3). Therefore, this research will look at whether small and medium sized enterprises may get a competitive usage from their social media usage.

\section{The benefits of Facebook usage for small and medium sized enterprises}

Today, many small and medium sized enterprises still primarily use paid media tools to advertise their products and services since they are not familiar with owned media tools (Lachove Marinello, 2010: 127). The main difference between paid media and owned media is that paid media consists of traditional media tools whereas owned media comprises social media tools. Newspapers, radio, television and advertisements are the chief tools of traditional media, which are indeed expensive to use for small and medium sized enterprises. On the other hand, owned media includes social media tools such as Facebook, Twitter, Instagram, Linkedin, Pinterest which are inexpensive to use for small and medium sized enterprises compared to paid media tools.

Facebook is still the most widely used social media platform in the world. Therefore, many small and medium sized companies, which are considered innovative, want to try Facebook to reach their potential customers. In fact, Facebook usage brings many benefits to small and medium size enterprises if they use it effectively. For instance, Nobre and Silva (2014) interviewed four small Portugese enterprises using Facebook and the results of their research indicated that Facebook helped these companies to find new customers, develop a closer relationship with theircurrent customers and increase sales (Nobre and Silva, 2014: 149).

Jones, Borgman and Ulusoy (2015) interviewed five small enterprises in Maine, U.S.A and arrived to the conclusion that Facebook helped these small enterprises to gain new customers with a lower cost compared to traditional media tools since Facebook can create business awareness andtarget specific people groups (Jones, Borgman and Ulusoy, 2015: 624). 
According to Lacho and Marinello (2010), a wedding photographer in the U.S.A couldn't gain as many customers as he wanted with traditional advertising. However, via Facebook, he limited his target audience and intended to reach merely young women. In addition, he shared a budget of 300 dollars only. In the end, he gained his business 60,000 dollars thanks to Facebook advertisements (Lacho and Marinello, 2010: 133). With a low budget shared for Facebook advertisements, this wedding photographer not only managed to get more photograph bookings, but also gained more profits.

Moreover, the example of Sleep Store which is a small sized enterprise in New Zealand shows that if small sized companies engage in dialogues with their customers, they can get the most efficiency from their Facebook usage as it will affect their sales positively. Hopkins (2012) stated that when Sleep Store opened a Facebook page in the beginning, the site only provided information about baby products. However, whenever the owners of the store turned their Facebook page into a discussion platform about baby care and responded to their customers' questions, they reached to 9,750 likes quickly and increased their sales (Hopkins, 2012: 135-137).

Furthermore, the research of Broekemier, Chau and Seshadri (2015) which was conducted on 81 small and medium sized enterprises in the U.S.A demonstrated that social media usage enhances the reputation of companies, draw the attention of new customers, bring better search rankings, improve web traffic to the website and help to create a bond with customers through dialogues (Broekemier, Chau and Seshadri, 2015: 42-43). As it is seen from the various examples mentioned above, social media usage will bring many benefits to small and medium sized enterprises if it is used effectively.

\section{Purpose and method of the research}

The number of researches which are made concerning the Facebook usage of small and medium size Turkish companies are very limited in the literature. This research aims to shed light on how small and medium size Turkish tourism agencies use Facebook for business purposes and whether they may get a competitive advantage from their Facebook usage. The sample of the research consists of seven tourism agencies, three of which are considered medium sized enterprises and four of which are considered small sized enterprises. These tourism agencies are located in Eskişehir, which is a northwestern city in Turkey. In this qualitative research, in-depth interviews were made with the Facebook representatives of tourism agencies on 23.09.2017. In the analysis part of the research, the researcher used descriptive analysis and created thematic codes.

\section{Results}

a) The time when they opened a Facebook account

According to the statements of small and medium size tourism agencies, most of them have been using their Facebook brand fan page actively for four to five years. Only one of the social media representative of a medium size tourism agency said that they have a Facebook page for twelve years but they have been using it professionally since the last two years.

\section{b) Technological capabilities of the social media representatives}

Most of the social media representatives of the small and medium size tourism agencies don't have a special education in internet and computer technologies. They don't have a training in how to use their Facebook brand fan page professionally. They said that they are familiar with Facebook and they think that they are using Facebook just like an ordinary person. While the owners of the small tourism agencies manage their company's Facebook account, the person in charge of the cultural tours department or a sales representative in medium size tourism agencies manage their company's Facebook brand fan page. There is only one IT department responsible from the 
Facebook account of a company among all the small and medium size tourism agencies interviewed.Moreover, one of the social media representative of a medium size tourism agency know how to design content for their Facebook page as he is a graduate of cartoons and animation.

Company A: $I^{\prime} m$ the responsible person from the cultural tours.Before being an administratorfor the company's Facebook account, I had managed my own Facebook account. I have been using the internet for fifteen years.

Company B: Different people are responsible from the Facebook account, to be exact, the owners of the company, the IT department and the cultural tours department.

Company C: Not only one person manages it.One of the administrator is I, one of them is our manager and one of them is our sales manager. I'm a graduate of cartoons and animation. I do not have much knowledge concerning the Internet technologies. I mostly create content and share the contents that I have created on Facebook.

Company D:I'm a sales representative. I use Facebook just like a regular person.

Company E:I'm the owner of the company. I've been using computers and the Internet for a long time.

Company F:Three people manages the Facebook account of our company. I work as a manager. We do not have a special education in Internet technologies. Since we all have a university education, we know how to use Facebook.

Company G: Everybody has a Facebook account. Using it consciously is enough.

\section{c) The aims of using Facebook for business purposes}

All of the small and medium size tourism agencies announce the dates and prices of their cultural tours from their Facebook brand fan page. Furthermore, they share their campaigns, let their customers know about their promotions, advertise their hotels, inform their customers about early booking advantages from their Facebook brand fan page. In addition, they celebrate the special days and official holidays of their customers from their Facebook brand fan page. Most of the small and medium size tourism agencies said that they use Facebook because it is a beneficial tool for advertisements.

In addition, they think that Facebook is a great tool to reach as many people as they target thanks to sponsored advertisements. The social media representatives of small and medium size tourism agencies said that they choose the age, gender and location of their customers and advertise their cultural tours on Facebook. They said that Facebook is useful in pulling new customers. Also, they said that during their conversations with their customers on their brand fan page, they invite their customers to their offices to talk face to face or take their e-mail addresses and send them detailed e-mails about their cultural tours or hotels afterwards.

Also, the social media representative of a small size tourism agency indicated that Facebook is a favourable tool for electronic word of mouth. When their customers write positive comments about their tours and share it on their company's brand fan page, then many people including the friends list of the person who has written the comments and the followers of the travel agency see that comment on Facebook. According to this social media representative, this is another way of advertising the tourism agency as electronic word of mouth creates an influence on other customers.

Company A: We share our cultural tours and activities on Facebook. Also, we share our hotel campaigns. We use Facebook for the purpose of an advertisement. We announce our tours to our prospective customers.

Company B: We usually give advertisements from Facebook. We give the advertisements of our tours and early booking advantages of hotels. We try to reach as many people possible from Facebook. 
Company C: We generally use Facebook to let people know about our tours. In addition, we introduce our hotels, we announce our promotions and we celebrate special days on Facebook.

Company D:We use it mostly for promotion. We share our hotels in campaign, we share the prices of our hotels and tours.

Company E:We use Facebook for advertisements. However, we invite our customers on Facebook to our tourism agency to talk face to face or we send e-mails.

Company F:We share our cultural tours and our hotels. We use it for promotion.

Company G:We opened our Facebook page just for promotion. Then we realized that the comments of our customers on Facebook have an influence on other customers' preference of our tourism agency. Then we started to use the positive comments of our customers by sharing them on Facebook. This way, our other customers could see those positive comments.

\section{d) The advantages of using Facebook}

Small and medium size tourism agencies which were interviewed think that social media usage is the new trend of our era. Also the social media representative of a medium size tourism agency stressed that the return of social media is indeed more than traditional media tools. He underlined that social media is ahead of traditional media tools because many people pay more attention to Facebook advertisements than posters hanged on windows. Furthermore, according to this social media representative many of their customers said that they had become aware of their tours first from Facebook. Another social media representative of a medium size company said that nearly $\% 20$ of their customers come to their agency to register for their tours or hotels by being influenced from their Facebook advertisements. Therefore, this social media representative is in the opinion that Facebook creates brand awareness.

Also, another social media representative of a small tourism agency said that after seeing their advertisements on Facebook, people call them via telephone or come to their office to get either detailed information or register for their tours. All of the small and medium size tourism agencies stated that they gain new customers thanks to Facebook since it helps them to reach a wide audience quickly. In other words, Facebook has a role in increasing the demand for their cultural tours and hotel reservations. For instance, the social media representative of a medium size company said that they give Facebook advertisements in different regions of Turkey according to the tours they organize and gain new customers this way. Also, one of the social media representative of a medium size company said that more people have heard about their travel agency thanks to Facebook and a traffic has been occurred on their Facebook page. He said that they have realized this traffic from the increase of their Facebook fans.

Furthermore, the owner of a small tourism agency said that they cannot send text messages to all of their prospective customers because some people do not accept text messages which includes advertisements from companies. The new Turkish law gives the right to people to limit the text messages that they receive from companies. Therefore, he thinks that Facebook gives them flexibility in reaching new customers. Also, an owner of another small size tourism agency said that some of their customers hear about their tourism agency through the electronic word of mouth that occurs on their Facebook page. He said that Facebook's atmosphere is suitable for electronic word of mouth. Accordingly, his customers recommend his tourism agency to their friends on Facebook and this way many people get a chance to learn about his tourism agency.

Company A:Social media is definitely more effective than the posters we hang on our windows. With the sponsored advertisements we give on Facebook, we can reach hundred thousands of people which is very advantageous. Most of the people who come 
to our agency first see us on Facebook and then come to our agency to talk with us.Social media is one step further.

Company B: Facebook increases awareness towards our company. For instance, nowadays we give advertisements in the Central Anatolia region of Turkey on Facebookand we can change the regions from time to times according to the tours we organize. We pull more customers thanks to Facebook. Nowadays, \%20 percent of our customers on average come to our agency by saying that we have seen you on Facebook first.

Company C: Facebook helps us to reach more people certainly. More people have a chance to get to know about us through Facebook. The number of our followers have been increased on Facebook. Therefore, we try to put more emphasis on Facebook.

Company D: Facebook increases the demand to our tours. Peoplewho see our advertisements on Facebook reach us via telephone or come to our office.

Company E: Because of the new Turkish law, sending text messages to customers through mobile phone is limited. Also, it is not possible to send pictures through text messages and the character number is limited in text messages. Facebook gives you flexibility in this issue.

Company F:We find new customers through Facebook. We usually give sponsored advertisements about our tours and hotels on Facebook.

Company G:Nowadays, people have started to search for information on Facebook before visiting the company websites. We get feedback from our customers on Facebook. For instance, our customers write about their vacations that they have bought from us on Facebook and their friends see that. It turns into word of mouth marketing.

\section{e) Time and budget shared for Facebook}

The budget that medium size tourism agencies share for their Facebook usage is higher than small size tourism agencies. The budget that medium size companies share for Facebook monthly changes between 300 Turkish Liras to 1.000 Turkish Liras. Also, a social media representative of a medium size tourism agency said that they spend nearly 7.000 to 8.000 Turkish Liras for Facebook yearly.

However, small size tourism agencies cannot keep up with the budgets of medium size companies. An owner of a small size tourism agency said that he can't share a budget for Facebook anymore as he cannot find time to take care of his agency's Facebook page. He thinks that he needs to find a full-time employee who can manage his tourism agency's Facebook page. He said that he definitely feels the deficiency of a full-time employee who can handle his tourism agency's Facebook page.

A social media representative of a medium size tourism agency said that they decide to increase the number of their Facebook advertisements in accordance with the seasons of the year. While they advertise their hotels in summer, they announce their early booking advantages in winter. An owner of another small size tourism agency said that they give emphasis to Facebook advertisements if a hotel that they sell doesn't have its own Facebook page. All of the social media representatives of medium size enterprises said that they are on Facebook all day when they are at the office. One of them said that he spends nearly two hours a day for giving responses to their customers on Facebook.

Company A: We share 1.000 Turkish Liras as a budget for Facebook monthly. I'm on our company's Facebook account all day. I'm on Facebook all day, but I virtually spend two hours a day totally on our company's Facebook page. I not only write answers but also share content with our followers.

Company B:In the beginning of the season we prepare a budget. We share around 7.000 and 8.000 Turkish Liras yearly for Facebook. We usually use the whole budget within a year. I check our company's Facebook account all day. Also, even if I am not in the office, our IT department takes care of it. 
Company C:We usually share 300 to 500 Turkish Liras monthly for Facebook advertisements. Actually, how much money we want to spend depends on the tours or hotels that we want to promote in that period. We try to share a budget for Facebook mostlyduring the times when we are busy. For instance, during summer we only promote hotels. We get benefit from Facebook the mostduring the early hotel bookings in winter and spring.

Company E:In the beginning, I spent a lot of time and budget for Facebook. But, nowadays I can't. I'm very busy in my job. I need to hire a person just for Facebook. Somebody who is trained in social media needs to take care of my social media accounts. That would be the best.

Company G: The budget that we spend on Facebook changes according to the seasonal efficiency. Furthermore, if a hotel that we promote doesn't have its own Facebook page, we spend more money on its advertisement on Facebook.

\section{f) Making a plan for the flow of the Facebook page}

All of the social media representatives of the medium size tourism agencies said that they make a plan about what they will share on their Facebook page seasonally, however this is not the case for some of the small tourism agencies. All of the Medium size tourism agencies said that they avoid making arbitrary Facebook shares on Facebook. Also one of the social media representative of a medium size tourism agency said that they receive a SEO service for their Facebook page and website.

Company B: Of course, we make a meeting in the beginning of the year to decide what kind of content we will share during the year. We do not share content randomly.

Company C:I make a planning together with the managers working here. We also get a professional SEO service.

\section{g) Interaction with customers on Facebook}

A social media representative of a medium size tourism agency said that people prefer reaching them via Facebook rather than telephone nowadays as people find sending private messages from Facebook more convenient. On the other hand, a social media representative of a medium size tourism agency said that since they are a wellknown tourism agency their customers think about coming to their tourism agency to talk face to facerather than reaching them via Facebook first. Most of the medium size tourism agencies said that they try to answer the questions of their customers on Facebook. For instance, one of the medium size tourism agency who has an IT department said that they try to answer their customers' messages in 2 minutes maximally for customer satisfaction.

However, a social media representative of a medium size agency said that their customers often send them private messages and they answer the private messages of their customers on Facebook. He said that the interaction ratio is low on their Facebook brand page. Nearly all of the small and medium size companies stated that their interaction with their customers is low on their Facebook brand page. But, social media representatives said that they try to give a reply to their customers' comments when they write something under the photos they share related with their tours. Furthermore, an owner of a small tourism agency said that Facebook is helpful to their business because he can gather the personal information of their customers easily from Facebook. Afterwards, he sends text messages to his customers during special days.

Company A:Some people constantly write about our tours on Facebook. People do not prefer reaching us via telephone anymore, people send messages from Facebook and other people make comments from Facebook.

Company B:We try to answer our customers' messages or comments on Facebook in 2 minutes maximally. 
Company C:We abstain from having a one-way communication on Facebook. We try to answer the questions of our customers on Facebook. But the interaction ratio is low. Since we are a well-known tourism agency in Eskisehir, our customers mostly prefer coming to our office in order to ask questions.

Company D:We try to answer the questions of our customers who make comments or send messages but the interaction is low.

Company E:There is limited interaction.

Company F:Our customers make comments under the photos we share and an interaction occurs when we engage into a dialogue with them.

Company G: We get personal information from our customers on Facebook. Then we send text messages during the holidays.

\section{h) Future plans of making the Facebook brand fan page better}

All of the small and medium size enterprises which were interviewed said that they want to improve their Facebook brand fan page in the future. A social media representative of a medium size tourism agency said that they want to create content which includes videos. Moreover, he said that they want to broadcast these videos not only on Facebook but also in YouTube. This way, he thinks that they will reach more people. A social media representative of another medium size tourism agency said that they want to give more sponsored advertisements on Facebook to reach masses. Nearly all of the small size tourism agencies said that their plan is to hire an employee who has a professional training in internet technologies. Their goal is to increase the number of their followers on their Facebook page thanks to the help of this professional employee understanding from digital technologies.

Company B:Our plans is related with advertisements totally. In order to increase interaction, we will try to give more sponsored advertisements.

Company C:We want to create content with videos. We want to make a preparation for that. We want to connect our videos into YouTube and we want our videos to be spread to more people.

Company D:We need to work with somebody who is professional in using Facebook brand fan pages.

Company E:If I can share time for Facebook, I will make it better. My only problem is finding the time.

Company F:Our goal is to increase our followers.

Company G: Firstly, we need to work with somebody who only understands from Facebook. This person needs to use hashtags more consciously. Secondly, we need to share a certain budget for that.

i) Disadvantages of local small and medium size tourism agencies compared to large size national tourism agencies in terms of using Facebook

Nearly all of the small and medium size local tourism agencies feel regret to the fact that they cannot share a big budget for their Facebook page. They said that the budgets of large size national tourism agencies is so high and it is not possible for them to spend as much money as large size national tourism agencies. However, since the budget of large size national tourism agencies is higher, they can give more sponsored Facebook advertisements to a wide audience and hire social media professionals to take care of their Facebook brand fan pages professionally. Therefore, small and medium size tourism agencies are in the opinion that their influence on masses is limited. For instance, the social media representative of a medium size tourism agency said that large size national tourism agencies give advertisements on Facebook not only in Turkey but also in abroad. However, medium size tourism agencies only address to local regions where they are located. Therefore, their Facebook advertisements are not visible within 
the whole country. As a result, medium and small size tourism agencies cannot get return from many customers just as large size tourism agencies.

Another disadvantage of small and medium size tourism agencies is related with not having a professional technical staff. Since small size tourism agencies do not have social media experts working for them or since they are not getting help from digital agencies, they cannot keep their Facebook page up-to-date. Furthermore, small size tourism agencies cannot create fresh daily content for their Facebook page to keep the site interesting enough for their customers. Moreover, some of the small size tourism agencies are not fast enough to reply their customers' responses in time to keep the dialogue going. Therefore, the level of interaction is low on their Facebook brand pages.

Company A: Big tour operators can reach more people within the country. Our influence area is limited. We address to 150.00 people they can address to 75 million people.

Company B:Since we have a limited budget compared to big tour operators we have certain disadvantages. Big tour operators can give advertisements to the whole Turkey and some foreign countries additionally. We can only give advertisements to our region or some neighbour regions. Of course, this limits our visibility. While they can give advertisements in whole Turkey we can give advertisements in rural areas or in our local region.

Company C:The Facebook shares of big tour operators can reach to more people. Local tourism agencies have a limited budget. They need to follow a small and more environmental advertisement plan. Of course big tour operators can spread their messages to more people and give people the feeling of trust.

Company D:Sometimes we can turn our customers' questions late on Facebook. Big tour operators have an employee who only takes care of Facebook. However for us timing can be an issue. The date of things we share on Facebook sometimes can pass our Facebook page is not always current. We need to handle that.

Company E:We do not have an employee who takes care of social media. Big tourism agencies work with digital agencies or people who are professional in this. Their job is to create content for social media, Facebook, Twitter, Instagram from morning to evening and to share it. They inform the related departments concerning the feedback of their customers. Since we do not have such an employee, we are not prompt in answering the questions of our customers, this is our problem.

Company F:Since big tour operators invest more on Facebookas they have a large budget, they have more followers. There is of course a difference between a Facebook brand fan page with 250 thousand followers and 5 thousand followers. When I share a tour, I get response from 20 to 30 people however large tour operators get response from 100 to 150 people.

\section{j) Whether Facebook usage may bring a competitive advantage to small} and medium size enterprises

Nearly all of the medium size tourism agencies think that by using Facebook, they get a competitive advantage but small size tourism agencies are not in the same opinionas they think that large size tourism agencies are way ahead of them in terms of Facebook usage. On the other hand, medium size tourism agencies profoundly think that they mostly get a competitive advantage from being a well-known and established local tourism agency in Eskisehir. They said that they have been giving a service in Eskisehir for many long years and local people prefer them before going to Istanbul originated big tourism agencies having a branch in Eskisehir first.

Company A: Of course Facebook gives us a competitive advantage. In addition, we are the oldesttourism agency in Eskisehirwe get the benefit of it in competition with big tourism agencies. People choose us because of our experience. In comparison with small tourism agencies, the budget that I share is not the same with the budget they share on 
Facebook. I reach to 200 thousand people with Facebook but small tourism agencies are limited with 10 to 20 thousand people.

Company B:It gives us a competitive advantage certainly. Big tour operators which are located in Istanbul have hotels which they are in charge of within their bodies. On the other hand, we have some hotels that we are in charge of in the central Anatolia region that we promote on Facebook. Local people in Eskisehir prefer local agencies compared to large size tourism agencies in Istanbul and this gives us a plus.

Company C:We partially gain a competitive advantage from our Facebook usage. Since we are not in the same level them with them it is hard for us to compete. Big tour operators give a more professional service than us. We try to give a service similar to them from Facebook.

Company D: I don't think we get a competitive advantage. First of all, we do not have the same number of followers just as much as big tour operators. We do not share the same budget for Facebookwell. I can only give sponsored advertisements for 10 days. We cannot reach to the same masses that big tour operators can reach.

\section{Discussion}

The major disadvantage of small and medium size tourism agencies in Eskisehir regarding their Facebook usage are related with time, budget and technical staff, which are supported by the literature. In order to compete with large size tourism agencies comfortably in terms of Facebook usage, small and medium size tourism agencies need to invest more to their companies and share a bigger budget for their Facebook pages. Also, small and medium size tourism agencies need to hire at least one full-time employee who has a special training in internet technologies. This employee especially should have an experience in how to manage a Facebook brand fan page effectively. Also, this employee needs to manage their Facebook brand fan page 24 hours a week by answering the questions, suggestions and complaints of their customers in time because most of the small and medium size tourism agencies interviewed said that they are not good in that. The common problem of most of the small and medium size tourism agencies is that they lack the sufficient resources to manage their Facebook page professionally.

While medium size tourism agencies think that Facebook helps them to get a competitive advantage, small size tourism agencies think that there is major gap between their Facebook usage and big tour operators' Facebook usage. Therefore, local and small size tourism agencies think that they cannot catch up with large size national tourism agencies' Facebook usage since large size tourism agencies are many steps further from them in terms of Facebook usage. They said that large size tourism agencies are more visible on Facebook since they can give more sponsored advertisements and their influence or impact area is much wider on Facebook. On the other hand, medium size tourism agencies think what gives them a competitive advantage most is their deeprooted history in Eskisehir. They said that they have been giving a service in Eskisehir before big tourism agencies opened branches in Eskisehir. Therefore, these medium tourism agencies said that since they are well-recognized tourism agencies in Eskisehir, local people prefer them first before going to big tour operators' branches in Eskisehir. Therefore, being "local" is a factor which plays an important role in giving a competition advantage to medium size tourism agencies in Eskisehir.

\section{References}

Banyai, E. (2016). The Integration of Social Media into Corporate Processes, Society and Economy, 38 (2), 239-259.

Beesly, C. (2013). Don't Be a Social Media Marketing Skeptic - Learn Where and How to Start, U.S Small Business Administration Blogs Managing a Business, Access Date: 6.09.2017, https://www.sba.gov/blogs/dont-be-social-media-marketing-skepticlearn-where-and-how-start 
Broekeimer, G., Chau, N. N. and Seshadri, S. (2015). Social Media Practices Among Small Business-to-Business Enterprises, Small Business Institute Journal, 11 (1), 37-48.

Carlota, L.R., Constantinides, E., Maria-del-Carmen, A.A. (2013). Social Media as Marketing Strategy: An Explorative Study on Adoption and Use by Retailers, Social Media in Strategic Management, 197-215.

He, W., Wang, F.K., and Zha, S. (2014). Enhancing Social Media Competitiveness of Small Businesses: Insights From Small Pizzerias, New Review of Hypermedia and Multimedia, 20 (3), 225-250.

Hopkins, J. L. (2012). Can Facebook be an Effective Mechanism for Generating Growth and Value in Small Businesses? Journal of Systems and Information Technology, 14 (2), 131-141.

Jones, N., Borgman, R. and Ulusoy, E. (2015). Impact of Social Media on Small Business, Journal of Small Business and Enterprise Development, 22 (4), 611-632.

Kadam, A. veAyarekar, S. (2014). Impact of Social Media on Entrepreneurship and Entrepreneurial Performance: Special Reference to Small and Medium Scale Enterprises, SIES J ournal of Management, 10 (1), 3-11.

Karimi, S., Naghibi, H. (2015). Social Media Marketing Strategies for Small to Medium Enterprises, International J ournal of Information, Business and Management, 7 (4), 86-98.

Kasteler, J. (2011). The Difference A Company's Size Makes in Social Media, Search Engine Land, Access Date: 27.09.2017, http://searchengineland.com/thedifference-a-companys-size-makes-in-social-media-77802

Lacho, K. J. and Marinello, C. (2010). How Small Business Owners Can Use Social Networking To Promote Their Business, The Entrepreneurial Executive, 15, 127133.

Nobre, H. and Silva, D. (2014). Social Network Marketing Strategy and SME Strategy Benefits, Journal of Transnational Management, 19, 138-151

Roy, A. and Dionne, C. (2014). Social Media: How Small and Medium Sized Enterprises Perceived and Used Them? The European Conference on Social Media Proceedings Book, 449 - 455, Brighton, UK: University of Brighton.

Roy, A., Maxwell, L., Carson, M. (2014). How is Social Media Being Used By Small and Medium Sized Companies? J ournal of Business and Behavioural Sciences, 26 (2), 127-137.

Zephoria Digital Marketing (2017). The Top 20 Valuable Facebook Statistics Updated August 2017. Access Date: 22.08.2017, https://zephoria.com/top-15-valuablefacebook-statistics 